\title{
A comparison of overshoot modelling with observations of polar mesospheric summer echoes at radar frequencies of 56 and $224 \mathrm{MHz}$
}

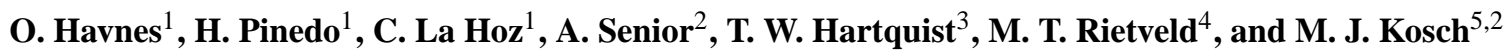 \\ ${ }^{1}$ University of Troms $\varnothing$, Institute of Physics and Technology, 9037 Troms $\varnothing$, Norway \\ ${ }^{2}$ Lancaster University, Department of Physics, Lancaster LA1 4YB, UK \\ ${ }^{3}$ University of Leeds, School of Physics and Astronomy, Leeds LS29JT, UK \\ ${ }^{4}$ EISCAT Scientific Association, Ramfjordmoen, Norway \\ ${ }^{5}$ South African National Space Agency, Hermanus 7200, South Africa
}

Correspondence to: O. Havnes (ove.havnes@uit.no)

Received: 20 February 2015 - Revised: 20 May 2015 - Accepted: 21 May 2015 - Published: 16 June 2015

\begin{abstract}
We have compared radar observations of polar mesospheric summer echoes (PMSEs) modulated by artificial electron heating, at frequencies of $224 \mathrm{MHz}$ (EISCAT VHF) and $56 \mathrm{MHz}$ (MORRO). We have concentrated on 1 day of observation, lasting $\sim 3.8 \mathrm{~h}$. The MORRO radar, with its much wider beam, observes one or more PMSE layers all the time while the VHF radar observes PMSEs in $69 \%$ of the time. Statistically there is a clear difference between how the MORRO and the VHF radar backscatter reacts to the heater cycling ( $48 \mathrm{~s}$ heater on and $168 \mathrm{~s}$ heater off). While MORRO often reacts by having its backscatter level increased when the heater is switched on, as predicted by Scales and Chen (2008), the VHF radar nearly always sees the "normal" VHF overshoot behaviour with an initial rapid reduction of backscatter. However, in some heater cycles we do see a substantial recovery of the VHF backscatter after its initial reduction to levels several times above that just before the heater was switched on. For the MORRO radar a recovery during the heater-on phase is much more common. The reaction when the heater was switched off was a clear overshoot for nearly all VHF cases but less so for MORRO.

A comparison of individual curves for the backscatter values as a function of time shows, at least for this particular day, that in high layers above $\sim 85 \mathrm{~km}$ height, both radars see a reduction of the backscatter as the heater is switched on, with little recovery during the heater-on time. These variations are well described by present models. On the other hand, the backscatter in low layers at $81-82 \mathrm{~km}$ can be quite different, with modest or no reduction in backscatter as the heater is switched on, followed by a strong recovery for both
\end{abstract}

radars to levels several times above that of the undisturbed PMSEs. This simultaneous, nearly identical behaviour at the two very different radar frequencies is not well described by present modelling.

Keywords. Atmospheric composition and structure (aerosols and particles)

\section{Introduction}

The polar mesosphere contains the visually observable noctilucent clouds (NLCs), the highest clouds in the Earth's atmosphere, observed at heights from $\sim 80$ to $\sim 90 \mathrm{~km}$. In the Northern Hemisphere the NLCs appear in May, when the temperature near the mesopause drops from a winter temperature around $220 \mathrm{~K}$ to sometimes as cold as $130 \mathrm{~K}$ (von Zahn and Meyer, 1989; Lübken, 1999), the coldest region on Earth. NLCs are visual manifestations of the polar mesospheric summer echoes (PMSEs) which are mainly observable by radar. The difference in visibility is a result of differences in dust/ice particles sizes. NLCs and PMSEs appear as temperatures become lower than $\sim 155 \mathrm{~K}$ (Cho and Röttger, 1997; Rapp and Lübken, 2004; Friedrich and Rapp, 2009), when water ice nucleates, possibly on meteoric smoke particles (MSPs) (Hunten et al., 1980; Rapp and Thomas, 2006; Megner, 2007; Ogurtsov and Raspopov, 2011). It appears that the icy NLC/PMSE particles also act as sinks for metallic atoms injected into the upper mesosphere by evaporating meteors (Plane, 2004; Lübken and Höffner, 2004; She et al., 2006, Raizada et al., 2007). They therefore do not consist 
only of water ice but can also contain meteoric material in atomic and molecular form. In addition to this, they probably contain large numbers of MSPs embedded in them (Havnes and Næsheim, 2007; Hervig et al., 2012; Kassa et al., 2012; Havnes et al., 2014).

The mesosphere is at altitudes too high for balloons and too low for satellites, and in situ observations can only be done by rockets. Rockets have been essential in investigating the mesosphere, discovering, among other things, the extremely low mesopause temperature at $\sim 85 \mathrm{~km}$ height (Theon et al., 1967), the mesosphere temperature profile (Inhester et al., 1994; Lübken et al., 2002) and the turbulence distribution (Lübken et al., 1993, 2002), and they showed that dust could have a profound influence on the charge balance in the mesosphere (Pedersen et al., 1969; Havnes et al., 1996). However, launches of rockets to investigate the mesosphere are comparatively rare and other methods of investigations are necessary. Powerful remote sensing techniques using radars, satellites, lidars and other instruments have been developed and are major tools for investigating the mesosphere. One method is to observe the NLC/PMSE clouds by radar and at the same time modify their plasma environment by the use of artificial electron heating such as used by the EISCAT Heating Facility (Rietveld et al., 1993). That the NLC/PMSE radar backscatter could be affected by heating was first shown by Chilson et al. (2000), who demonstrated that, with heater cycles having equal and short (10$20 \mathrm{~s}$ ) on- and off-times, the radar scattering from PMSEs could practically disappear when the heater was switched on, and reappear at approximately the same intensity when the heater was switched off. This was explained by Rapp and Lübken (2000) as a result of changes in the electrostatic pressure when the electrons were heated, leading to reduced electron gradients and reduced radar backscatter. They also recognized that the dust charges would be affected by the heated electrons. Havnes (2004) and Havnes et al. (2003) predicted and demonstrated that, by using a comparatively short heater-on period of $20 \mathrm{~s}$ followed by a long heater-off period of $160 \mathrm{~s}$, thereby allowing the plasma and dust charges which had been influenced by the heated electron gas to relax back to their undisturbed equilibrium conditions, one could create an overshoot effect where the PMSE backscatter strength when the heater was switched off could jump to values several times higher than that before the heater was switched on. The initial models for the overshoot effect (Havnes, 2004; Havnes et al., 2004; Biebricher et al., 2006) assumed instantaneous adjustment of the electron and ion density when the heater was switched on and off. In addition to this the electron and ion density was assumed to be described by a Boltzmann distribution within the local scattering dust clumps or dust depletions (holes) of the NLC/PMSE clouds. Radar backscatter models from electron density gradients based on these assumptions reproduce well most of the cases where the overshoot effect was observed by high-frequency radars such as the EISCAT
VHF (224 MHz) and UHF (930 MHz) (Næsheim et al., 2008; Biebricher and Havnes, 2012). At these frequencies the most efficient backscatter dust irregularities, with sizes of half the respective radar wavelengths - the Bragg scale lengths are at 67 and $16 \mathrm{~cm}$ respectively. For such small dust inhomogeneity dimensions the plasma adjustment time will normally be shorter than the dust charging time and the instantaneous plasma adjustment model will for most cases be acceptable (Biebricher and Havnes, 2012). However, for lowfrequency radars such as the MORRO radar at $56 \mathrm{MHz}$ or the EISCAT HF at $8 \mathrm{MHz}$ (Senior et al., 2014), the Bragg lengths will be 2.7 and $38 \mathrm{~m}$ respectively. In such cases the plasma adjustment times can often be considerably longer than the dust charging time. Modelling shows that this can have a profound influence on the radar backscatter during a heateron and heater-off time cycle and the overshoot characteristic curve (OCC), the backscatter variation during one heater cycle (Havnes et al., 2004), can be very different from what it normally is for the EISCAT VHF and UHF frequencies (Scales, 2004; Næsheim et al., 2008, Scales and Chen, 2008, Mahmoudian et al., 2011; Biebricher and Havnes, 2012). In Fig. 4 we show an example of the "classical" OCC for an EISCAT VHF observation. We see a rapid initial weakening as the heater is switched on, some recovery of the backscatter during the time the heater is on (caused by additional charging of the dust by the heated electron gas) and thereafter the rapid overshoot as the heater is switched off, followed by a relaxation back to normal conditions. For wavelengths longer than the VHF, and occasionally for VHF also, the additional charging of dust by the heated electrons may occur as fast or faster than the plasma density adjustment. This can cause a rapid recovery of the backscatter signal after a brief weakening of the backscatter as the heater is switched on to a level above that before the heater was switched on. In more extreme cases, modelling shows that the backscatter may not even weaken but can apparently start to increase as soon as the heater is switched on, causing an onset overshoot (Scales, 2004; Chen and Scales, 2005; Scales and Chen, 2008; Mahmoudian and Scales, 2012). This has recently been observed by Senior et al. (2014) for a HF (7.953 MHz) radar collocated with the EISCAT VHF radar.

In the following we will focus on the observations by two radars, MORRO at $56 \mathrm{MHz}$ and EISCAT VHF at $224 \mathrm{MHz}$, both at the Troms $\varnothing$ EISCAT site $\left(69.6^{\circ} \mathrm{N}, 19.2^{\circ} \mathrm{E}\right)$, on one day during a Norwegian-UK campaign in July 2013. These are the first reported simultaneous and collocated PMSE observations at these two frequencies. The day, 26 July, was picked as it indicated the probable presence of an onset overshoot during parts of the observing time of $3 \mathrm{~h} 50 \mathrm{~min}$. We will examine to what degree the observed OCCs for the two radars, their similarities or differences, agree with predictions of existing models (e.g. Mahmoudian et al., 2011; Biebricher and Havnes, 2012). In Sect. 2 we compare the PMSE height profiles for the two radars to examine to what degree we find significantly different PMSE height profiles 

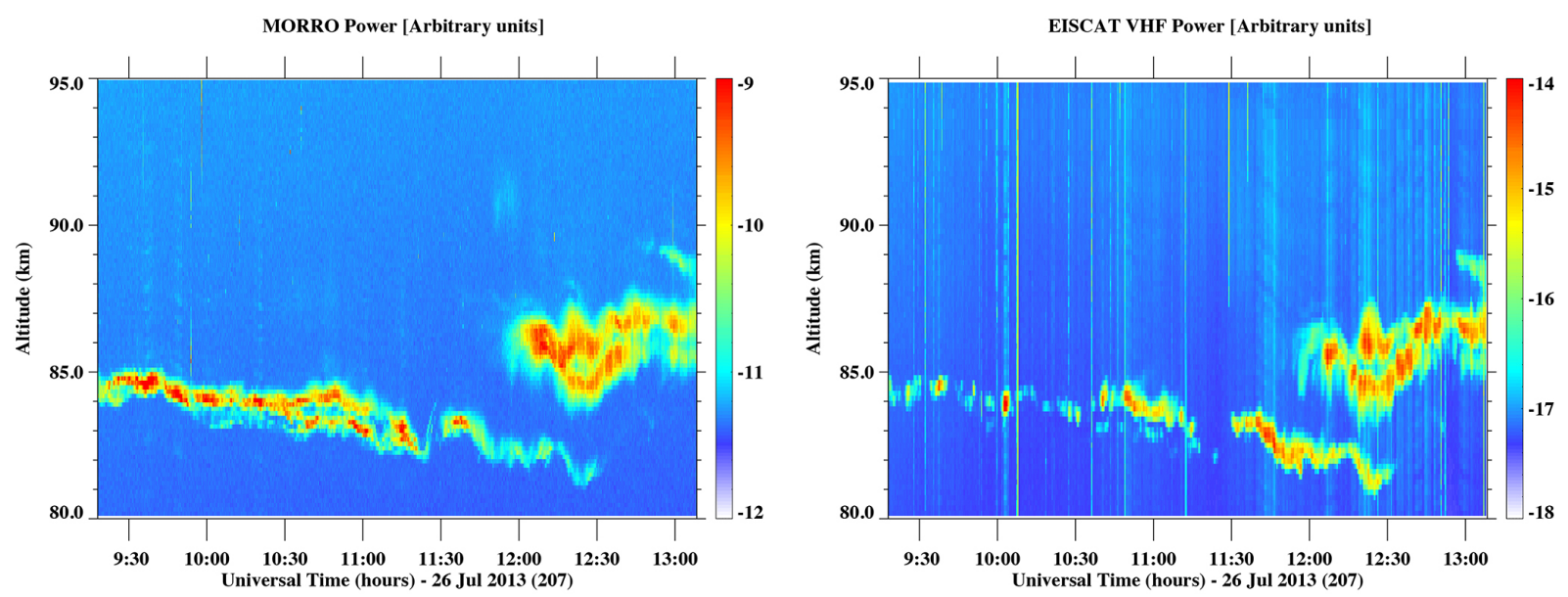

Figure 1. The overall view of the PMSEs on 26 July 2014 with the two radars MORRO at $56 \mathrm{MHz}$ and VHF at $224 \mathrm{MHz}$. The scale is in arbitrary units.

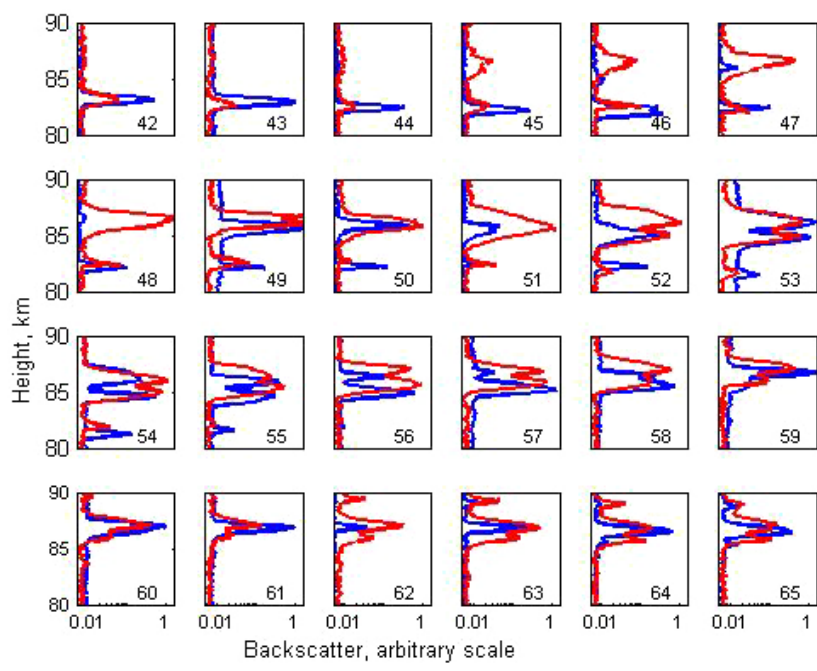

Figure 2. Vertical profiles of PMSEs for cycles 42 to 65 for the MORRO and VHF radars. The plotted profiles for each cycle correspond to the backscatter averaged over $10 \mathrm{~s}$ just before the heater is switched on. MORRO profiles are red; VHF profiles are blue. The cycle numbers are shown in the lower right-hand corners.

for the two radars. We thereafter look at the statistical properties of the OCCs for the two radars to see if they show clear differences and if those are compatible with model predictions. In Sect. 3 we compare several OCCs for two cases. The first case is one low layer where the backscatter is reduced by little or nothing immediately after the heater is switched on but where a strong increase in backscatter (recovery) builds up when the heater is on. The second case is for higher layers which show an OCC similar to that of Fig. 4, where the reduction in intensity is clear and present for both radars. Section 4 concludes the paper.

\section{Observations and statistics of heater-affected PMSEs at the radar wavelengths of 1.3 and $5.4 \mathrm{~m}$}

The observations presented here are part of a NorwegianUK campaign in July 2013 where EISCAT radars at frequencies of 7.953, 224 and $933 \mathrm{MHz}$ (Senior et al., 2014) and the University of Troms $\varnothing$ MORRO radar at $56 \mathrm{MHz}$ were used together with the EISCAT Heating Facility (Rietveld et al., 1993). The heater was run at $6.77 \mathrm{MHz}$ with effective radiated power (ERP) of $600 \mathrm{MW}$, in O-mode polarization. A main aim of the campaign was to look for cases where radar backscatter after the heater was switched on showed an immediate increase (onset overshoot) instead of reduction as in Fig. 4, and to compare the observed backscatter at different wavelengths (see also Senior et al., 2014). The onset overshoot appeared to be clearly present over a period of 15-20 min during 26 July. For this day we will look at the observations by the two radars MORRO and EISCAT VHF. See Fig. 1 for an overview of the PMSE layers as observed with the two radars. According to predictions based on numerical modelling, there should in general be a considerable difference between the OCCs observed for these radars with their different Bragg scatter scale length (Mahmoudian and Scales, 2012; Biebricher and Havnes, 2012)

MORRO has a total beam width of $\sim 7 \mathrm{~km}$ at the PMSE height, compared to $1.5 \mathrm{~km}$ for the VHF beam. PMSE structures which are within the MORRO beam and detected by it may therefore not necessarily be detected by the VHF radar. In Fig. 2 we show a comparison between the vertical profiles of PMSEs taken with MORRO and VHF for 24 heating cycles from 42 to 65 . The PMSE intensities as function of height which we show for each cycle are the average over an interval of $10 \mathrm{~s}$ just before the heater is switched on (R0; see Fig. 4). We see that there are several cases (e.g. cycles 45 to 48) where the MORRO radar shows a relatively strong and wide PMSE layer, while the VHF radar observes none, or a 

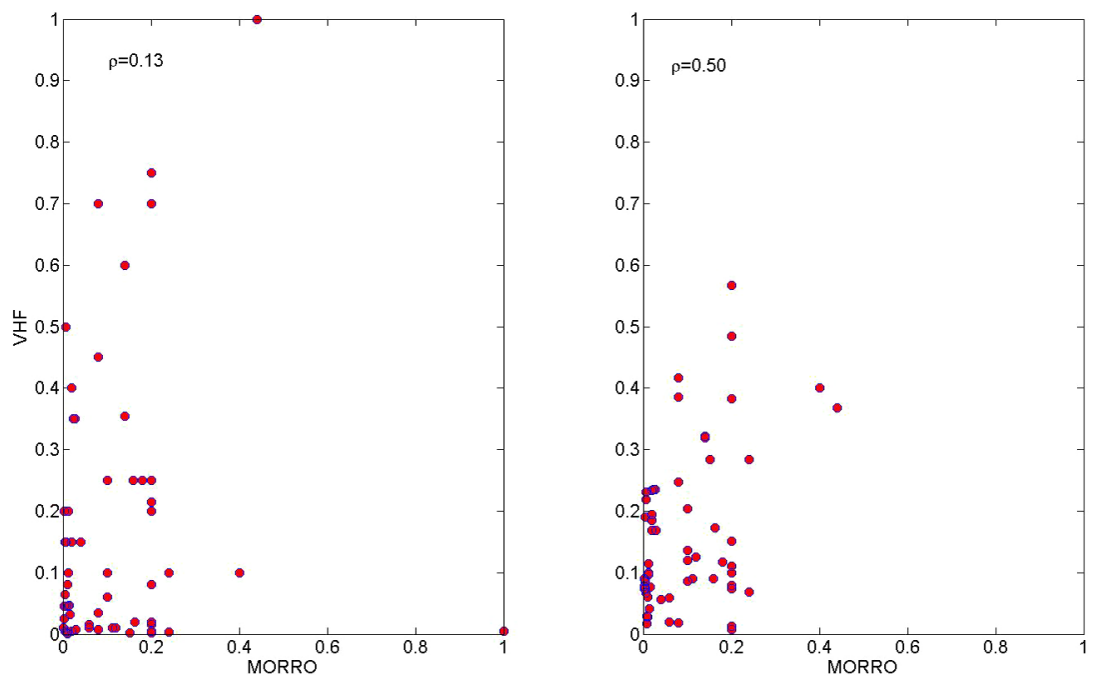

Figure 3. For each cycle and each PMSE layer in a cycle we plot the corresponding maximum PMSE values for the two radars. The left panel shows all points where both VHF and MORRO observe a layer. The scales are normalized by putting the largest maximum equal to 1 for both radars. In the right panel we have done a running mean over three data points. The linear correlation coefficient $\rho$ is given for each case.

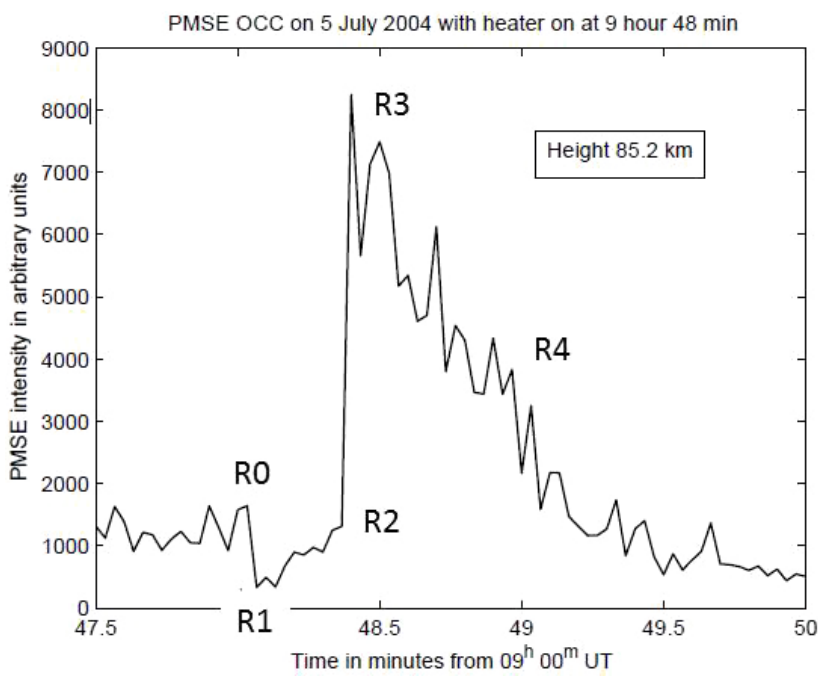

Figure 4. An overshoot characteristic curve (OCC) for VHF showing the backscatter sampling intervals R0, R1, R2, R3 and R4. The width of the sampling intervals can be changed. The heater is on from the start of the R1 interval to the end of the R 2 interval. See text for details.

weak PMSE. In a few other cases (e.g. cycles 50 and 55), we see the opposite behaviour, where VHF observes a moderately strong low PMSE layer while MORRO observes little or nothing of this layer. This last situation probably indicates a patchy horizontal structure of the low PMSE layer, which may occasionally fill some of the VHF beam but only a small fraction of the MORRO beam.

It is also clear that the shape of the turbulence spectrum must influence the strength of the radar backscatter and that it can affect the height profiles observed by the two radars. The turbulence, in combination with heavy charged dust particles (Kelley et al., 1987; Rapp and Lübken, 2004), creates small-scale structures both in dust and plasma density (Rapp and Lübken, 2003) In the PMSE region the volume reflectivity for the MORRO radar can apparently be from some hundreds to several thousands of times that of the EISCAT VHF radar (Rapp and Lübken, 2004), and this, together with a much wider beam, should favour the MORRO radar. If the difference in volume reflectivity is dominant in causing differences in backscatter between MORRO and VHF, we expect that there should be some correlation between the observations by the two radars. The correlation may be weak if the VHF Bragg scale is in the dissipation range of the spectrum (Rapp and Lübken, 2004). We searched for a correlation by examining the maximum backscatter for the two radars, for all the cycles and all the layers in them. In Fig. 3, left panel, we have plotted the 66 pairs of values where both MORRO and VHF observe the same PMSE layer. We see at best a very weak correlation with a linear correlation coefficient of $\rho=0.13$ as given in the figure. It is more conspicuous that there are 17 cases where MORRO sees a layer but where VHF does not, even if these cases involve the strongest MORRO backscatter. This is what we expect for the large difference in beam widths if the PMSE has a patchy structure which allows structures to be present in the MORRO beam but not in the VHF beam. We have also looked for effects of calculating a running mean for the VHF observations, after rearranging the data so that the MORRO backscatter is in ascending order. In Fig. 3, right panel, we show the effect of a running mean of three data points, which leads to a linear correlation coefficient of $\rho=0.50$. This indicates that much of 

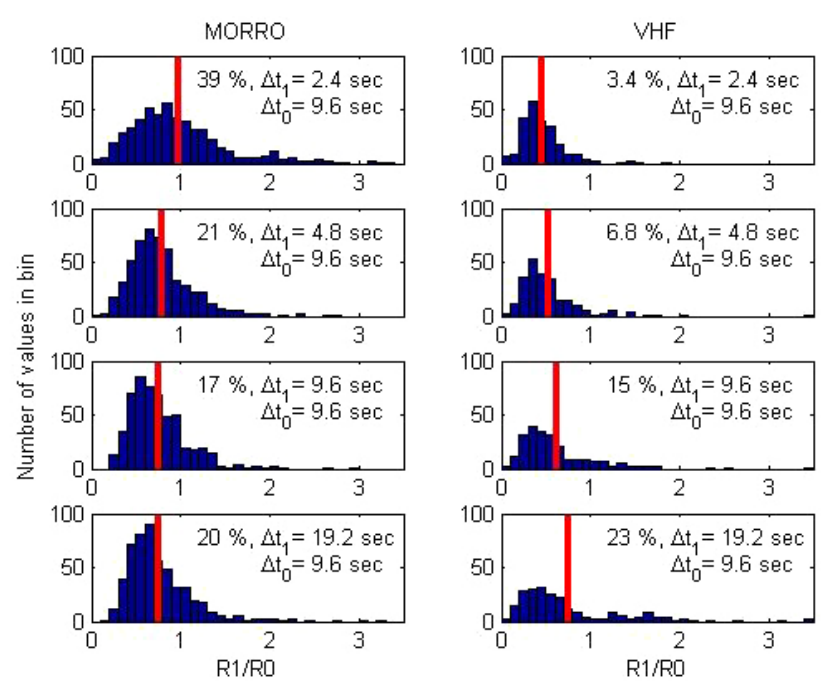

Figure 5. The distribution of the ratio R1/R0 for the MORRO radar and the EISCAT VHF radar. The percentage values refer to the fraction which has $\mathrm{R} 1 / \mathrm{R} 0>1$, indicating onset overshoots. The included ratios are for cases where the PMSE signal strength R0 is at least twice that of the background strength. The sampling time interval for R0 is $\Delta t_{0}=9.6 \mathrm{~s}$ for all cases, while $\Delta t_{1}$ is given values from 2.4 to $19.2 \mathrm{~s}$ as shown in the figures. The heater is on for $48 \mathrm{~s}$. The average values of $\mathrm{R} 1 / \mathrm{R} 0$ are indicated by the vertical red lines. For a case of $\Delta t_{1}=1.2 \mathrm{~s}$ (not shown) the percentages for MORRO and $\mathrm{VHF}$ with $\mathrm{R} 1 / \mathrm{R} 0>0$ are 40 and $2.1 \%$ respectively.

the variation from cycle to cycle is caused by a patchiness of the PMSE layer and that the effect of this is partly smoothed out in Fig. 3, right panel, to reveal the expected positive correlation between the backscatter for the two radars.

In order to discuss the variation of the backscatter throughout a heater cycle, characterized by the overshoot characteristic curves (OCCs), we will use the parameters R0, R1, R2 and R3 (Havnes et al., 2003), shown in Fig. 4, to obtain statistical information. R0 corresponds to the average of the backscatter within a given time interval, just before the heater is switched on. R1 is the average in an interval just after the heater has been switched on, while R2 is the average of an interval just before the heater is switched off again. R3 is the average of an interval just after the heater has been switched off, while R4 is the average some time after the heater has been switched off, in order to get a measure of the relaxation rate of the overshoot. R4 is not used in this paper. To reduce the effect of noise in the data, we average over a number of samples corresponding to a time interval of $\Delta t_{\alpha}$, where $\alpha=0$ to 4 . We will still maintain $\mathrm{R} 0$ as containing only data from before the heater is switched on, R1 and R2 containing data when the heater is on, and R3 and R4 containing data in the relaxation phase with no heater on. The OCCs displayed by the UHF and VHF radars (Havnes et al., 2004; Næsheim et al., 2008) normally have R1 / R0 < 1 as in Fig. 4, demonstrating that the backscatter weakens when the heater is switched on (Chilson et al., 2000). Depending on the recovery during the phase when the heater is on R2, which most often is less than R0, can be larger than R0 if the recovery is fast. For an onset overshoot we will have R1 / R0 > 1 (Scales, 2004; Chen and Scales, 2005; Biebricher and Havnes, 2012). Normally an overshoot is characterized by $\mathrm{R} 3$ / R $0>1$.

Figure 5 shows the distributions of the ratio R 1 / R 0 for the MORRO and VHF radars for different values of the sampling interval for R1. The immediate reaction of the backscatter to the heater being switched on is best demonstrated by the first row, which has a short sampling interval for R1 of $\Delta t_{1}=2.4 \mathrm{~s}$. The interval of $\mathrm{R} 0$ is $\Delta t_{0}=9.6 \mathrm{~s}$ in all cases. We see that there is a large difference between the distributions for MORRO and for VHF. While at best only a few cases with onset overshoot $(\mathrm{R} 1 / \mathrm{R} 0>1)$ are observed by the VHF radar, the situation is quite different for MORRO. At the shortest sample time, as many as $39 \%$ of the MORRO cases seem to experience the onset overshoot. Even if some of those cases may be due to noise effects, it is clear that MORRO observations far more often than the VHF observations show a near-to-immediate increase in the backscatter when the heater is switched on. This behaviour, which is contrary to the drop in intensity seen when heating effects were first observed in PMSEs by Chilson et al. (2000), and which was also found in later observations with VHF and UHF (e.g. Næsheim et al., 2008), was predicted by Scales (2004) to be present particularly for long-wavelength radars. The reason for this near-to-immediate increase in backscatter as the heater is switched on is that, for the larger dust density structures, which scatter at long wavelengths, the plasma density adjustment time can be longer than the dust charging time. In such cases the additional charging of the dust can be rapid enough to more than compensate for the effect of increased electron gas pressure on the plasma distribution when the electrons are heated. When electrons are heated the plasma density tends to be smoothed unless the additional dust charging is fast enough to counteract this. If plasma adjustment is the faster process, electron gradients will weaken and so will the backscatter. On the other hand, if dust charging happens fast enough, this will steepen the electron density gradients and increase the backscatter. If we increase the sampling time for R1 in Fig. 5, we see that for VHF the average of the ratio $\mathrm{R} 1 / \mathrm{R} 0$ and the percentage of cases with $\mathrm{R} 1$ / R0 > 1 steadily increases, indicating that for VHF there is often a considerable recovery of the PMSE strength after an initial rapid decrease as the heater is switched on. For the MORRO observations the situation is different. The drop to $21 \%$ when the sample interval for R1 is increased from 2.4 to $4.8 \mathrm{~s}$ for the MORRO data may partly be caused by averaging out noise effects. However, this behaviour is also qualitatively similar to cases which have been predicted (Scales 2004; Chen and Scales, 2005; Biebricher and Havnes, 2012) when conditions in the PMSEs are such that the plasma adjustment time is comparable to the dust charging time for heater-affected PMSEs. Chen and Scales (2007) show that a 

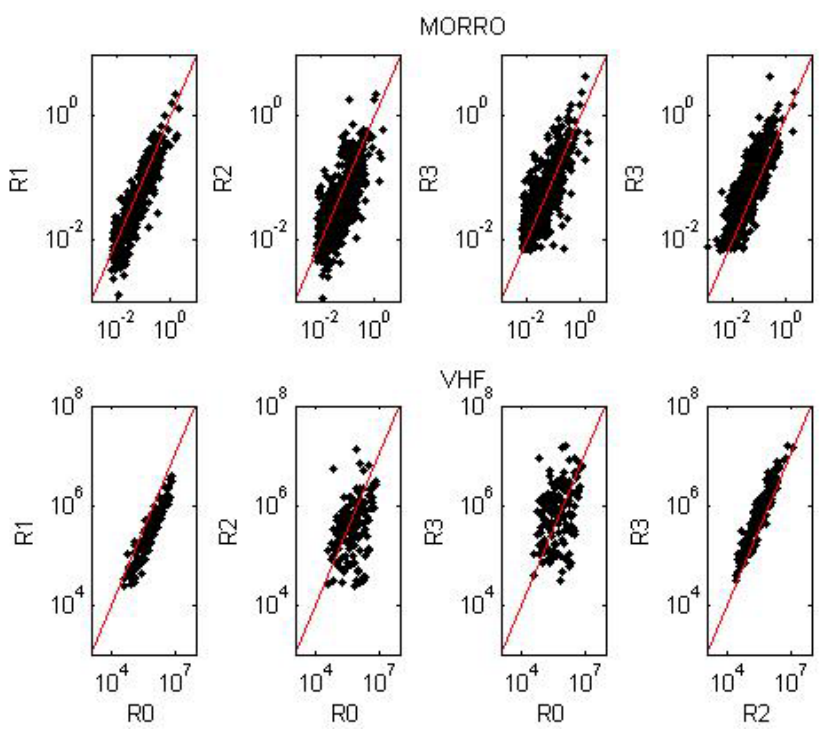

Figure 6. The relation between the strength of the different parameters R0, R1, R2 and R3. The sample times for R0 are $9.6 \mathrm{~s}$ for both MORRO and VHF, while the sampling times for R1, R2 and R3 are $2.4 \mathrm{~s}$ for $\mathrm{VHF}$ and $2.88 \mathrm{~s}$ for MORRO. The requirement for points to be included is that the value of R0 is twice or more than that of the background noise. The axes have arbitrary relative scales for each radar. The red lines give where the different ratios are equal to 1 .

brief onset overshoot can be followed by a drop in backscatter intensity. However, it is more surprising that, when the sampling time $\Delta t_{1}$ is increased to $19.2 \mathrm{~s}$, covering $40 \%$ of the time the heater is on, about $20 \%$ of the samples show a ratio of $\mathrm{R} 1 / \mathrm{R} 0>1$ for both MORRO and VHF. This is apparently contrary to model predictions (Mahmoudian et al., 2011; Biebricher and Havnes, 2012), which indicate that even if a radar at the MORRO frequency observes R1 > R0 for much of the time when the heater is on, the observations with the VHF radar should consistently show a much smaller value of R1 / R0, which even tends to be smaller than 1 (Biebricher and Havnes, 2012). The indications that the recovery of the VHF backscatter for a significant number of cases can be large, lends support to the finding by Senior et al. (2014) that there appears to be some additional charging effect which increases the space charge of the dust density structures during the heater-on time, compared to what the models predict. This is also needed in the models of Biebricher and Havnes (2012) to produce a sufficiently large recovery for VHF during the heater-on phase. We have no strong candidates for this but wonder whether this can have any connection to the surprising amount of positively charged nanometer-sized particles found within and near to NLCs and PMSEs by the dust probe MASS (Robertson et al., 2009).

In Fig. 6 we show more details on the difference between the OCC for MORRO and VHF by plotting the values of R1, $\mathrm{R} 2$ and R3 against the corresponding R0 or R2. The most obvious difference between the VHF and MORRO observations is that for MORRO there are no very strong tendencies. For all the distributions shown in Fig. 6 we find that for MORRO there are a comparable number of cases above and below the line in red at which the ratio is 1 . This is most likely a result of the fact that the MORRO radar wave scatters from sufficiently large structures so that the plasma adjustment time, depending on the dusty plasma conditions, can be both larger and smaller than the dust charging time when the heater is switched on or off. Lie-Svendsen et al. (2003) find a plasma diffusion time of $t_{\mathrm{d}, i} \sim 25 \mathrm{~s}$ for a scattering structure of $L=3 \mathrm{~m}$ at a height $85 \mathrm{~km}$. The diffusion time is proportional to $L^{2}$, so $t_{\mathrm{d}, i} \sim 1 \mathrm{~s}$ for the VHF structures. We make an estimate of the charging time $t_{\text {ch }}$ by calculating the time for the dust charge to be increased by one negative unit charge, $-\mathrm{e}$. Using the electron current $I_{\mathrm{e}}$ from, for example, Havnes (2004) we find $t_{\mathrm{ch}} \sim \frac{10^{4}}{r_{\mathrm{d}}^{2}} \mathrm{~s}$. We have used an ion mass number of 30 , a heated electron temperature of $300 \mathrm{~K}$, and an electron density of $2 \times 10^{9} \mathrm{~m}^{-3}$. This leads to charging times between 100 and $4 \mathrm{~s}$ for dust sizes from 10 to $50 \mathrm{~nm}$. For larger electron densities and higher heated electron temperatures, the charging time will be smaller. For the VHF the Bragg scale length is sufficiently small for a plasma adjustment time around $1 \mathrm{~s}$, when the heater is switched on or off, to be nearly always considerably shorter than the dust charging time. We see clearly from the distributions in the first column, showing R1 against R0, that MORRO has a considerable number of cases with both $\mathrm{R} 1>\mathrm{R} 0$ and $\mathrm{R} 1<\mathrm{R} 0$, while there are very few cases $(4.7 \%)$ for VHF with $\mathrm{R} 1>\mathrm{R} 0$. This also follows from the first row of Fig. 5. VHF generally shows the "classical" weakening, where R1<R0 (Næsheim et al., 2008). The second column indicates that for both radars there are many cases with sufficient recovery, even after a probable initial drop in intensity as the heater is switched on, to produce R2 > R0. However, it appears that in most cases the recovery is either not present or sufficiently low so that $\mathrm{R} 2<\mathrm{R} 0$. The third column shows that for both radars there are a comparable number of cases with overshoot $(\mathrm{R} 3>\mathrm{R} 0)$ as with $\mathrm{R} 3<\mathrm{R} 0$. The results in second and third columns may to some degree be affected by a drift of the NLC/PMSE clouds since the time between observing R0 and $\mathrm{R} 2$ or R3 is 52 and $54 \mathrm{~s}$ respectively. A drift of $\sim 50 \mathrm{~m} \mathrm{~s}^{-1}$ (Rapp et al., 2008) would move a PMSE edge $\sim 2.5 \mathrm{~km}$ horizontally. From Figs. 7 and 8, showing the OCC for several heater cycles, we occasionally see large deviations from the ideal OCC (Fig. 4) within such timescales. We also see from Fig. 2 that there can be a considerable change in the PMSE height profiles for both radars from one cycle to the other. This indicates that some change can, at least occasionally, be caused by new cloud material being brought partly into or out of a radar beam in the time interval from $\mathrm{R} 0$ to $\mathrm{R} 2$ or R3. The time differences between R0 and R1 in the first column and between R2 and R3 in the fourth column are only 6.4 and $2.8 \mathrm{~s}$ respectively. 


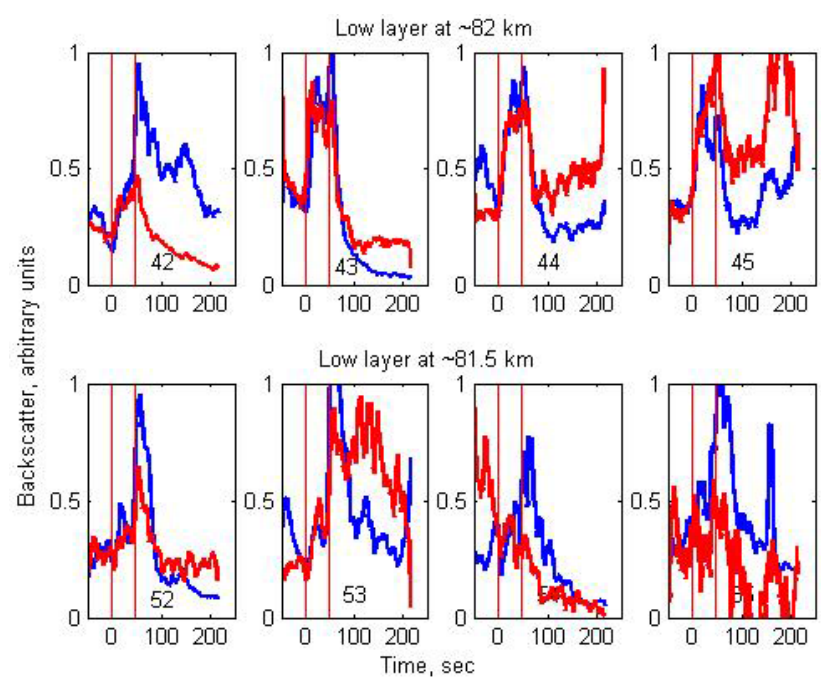

Figure 7. The OCC for four cycles for each of two low single layers at heights $\sim 82$ and $81.5 \mathrm{~km}$ shown on a linear scale from 0 to 1 . The OCCs for each cycle have been normalized to coincide at $t=0$. VHF is blue; MORRO is red. The heater is on between the two vertical red lines. Heater cycle numbers are given at the bottom of each figure.

The last column shows that VHF in the majority of cases reacts when the heater is switched off by rapidly increasing the backscatter so that R3 / R2 > 1. This is the overshoot which is expected from the first overshoot models and observations of it with VHF (Havnes et al., 2003). For MORRO the increase in backscatter $(\mathrm{R} 3 / \mathrm{R} 2>1)$ also dominates, but there are a significant number of cases with $\mathrm{R} 3 / \mathrm{R} 2<1$. Such cases have been found in models (Biebricher and Havnes, 2012) but for Bragg lengths longer than that for MORRO. The reason for this is again that, for large structures, the plasma adjustment time, after the heater is switched off, can be longer than the dust charge adjustment time.

\section{Individual OCC profiles for MORRO and VHF}

We now compare observations from MORRO with those of VHF for the same cycles and PMSE layers. We look at two different situations, and for each of them we will consider the OCC for four different cycles. In each cycle the OCC will be an average of the OCCs within a height interval of $1.35 \mathrm{~km}$ for MORRO and $1.62 \mathrm{~km}$ for $\mathrm{VHF}$, centred on the height with the strongest backscatter in the layer we consider. The first situation include the cycles from 42 to 45 , where VHF sees only one low PMSE layer at $\sim 82 \mathrm{~km}$ in all cycles. MORRO sees the same low layer in all the four cycles, but it also observes the start of an additional layer at $\sim 87 \mathrm{~km}$ in cycles 44 and 45, as can be seen from Fig. 2. The second situation involves the cycles from 52 to 56, where we have the same low layer, now at $\sim 81.5 \mathrm{~km}$, and also two higher layers, one at $\sim 85$ and one at $\sim 86 \mathrm{~km}$ height. In Fig. 7 we show the OCCs for the low PMSE layer as seen in cycles 42

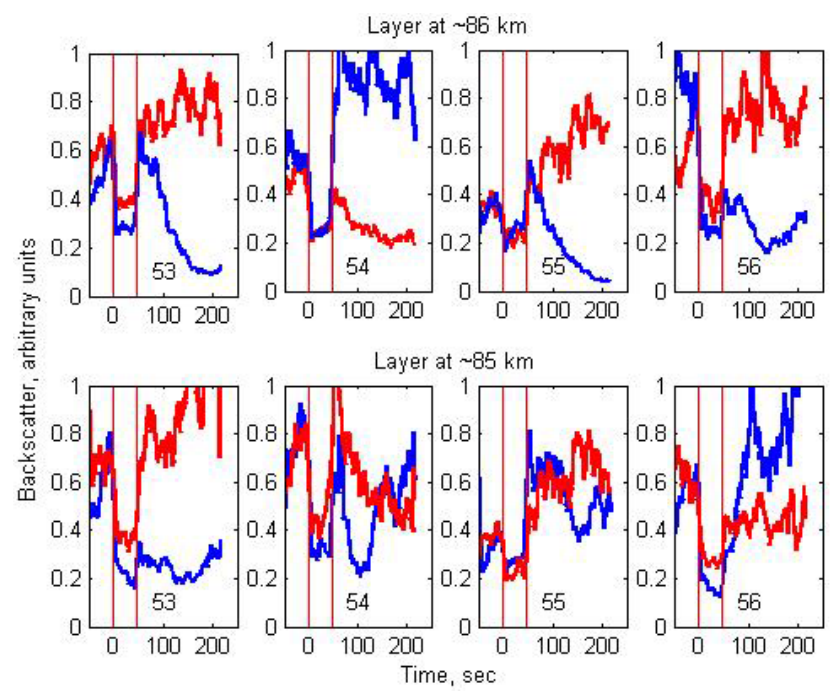

Figure 8. The OCC for the same four cycles for each of two different layers at heights 86 and $85 \mathrm{~km}$ shown on a linear scale from 0 to 1 . The OCCs for each cycle have been normalized to coincide at $t=0$. VHF is blue; MORRO is red. The heater is on between the two vertical red lines. Heater cycle numbers are given at the bottom of each figure.

to 45 , and the same low layer now in cycles from 52 to 55 . In both situations we have a situation which is very different from the classical overshoot behaviour of Fig. 4. There is little or no reduction of the backscatter power after the heater is switched on, but instead we see a very strong and rapid increase (recovery) of backscatter with time for both radars. This is most pronounced for the cycles from 42 to 45 . This recovery may flatten out, or even decrease, until the heater is switched off. The considerable overshoot for VHF and small overshoots for MORRO is again a consequence of the larger size and longer plasma adjustment time of the dust density structures which are scattering the MORRO beam.

All modelling so far predicts a considerable difference in the behaviour of the backscatter variation (OCC) for the radar frequencies of the MORRO and VHF radars. MORRO and lower-frequency radars may show an immediate increase in backscatter after the heater is switched on, while for the same conditions VHF has a tendency to observe a reduction of the backscatter (Mahmoudian et al., 2011; Biebricher and Havnes, 2012) or at least a much slower increase than for the MORRO frequency. We see from Fig. 7 that this is not the case for the cycles in these two low layers where both radar observations change in a similar way after the heater is switched on. The VHF, but not MORRO, does sometimes show a small initial decrease in backscatter, but thereafter both radars observe the same rapid and strong increase (recovery) in the backscatter which, to our knowledge, the present overshoot models do not fully predict. The way the increase in backscatter for both radars is reduced after 15 to $25 \mathrm{~s}$ from the time the heater is switched on is also qualita- 
tively similar, and both radars apparently see the same relaxation time, which we roughly estimate to be $\sim 50 \mathrm{~s}$. We find it likely that the overall physical conditions in the parts of the clouds which are within the two different radar beams are similar since they both show a stable low layer, at approximately the same height, over more than seven cycles corresponding to $\geq 25 \mathrm{~min}$.

In the second situation we observe multiple layers, in this case three layers at around 86,85 and $81.5 \mathrm{~km}$ respectively. In Fig. 8 we show the cycles from 53 to 56 for two upper layers, while for the lowest layer we showed cycles 52 to 55 in Fig. 7. The reason for this cycle shift is that for MORRO there is no low layer at cycle 56. We therefore shifted cycles for the low layer down by one.

As is already apparent from Fig. 2, the upper layers often show a considerable "activity" in the sense that the layers observed by MORRO and VHF often show different shifts in height and intensity. This is probably mainly a result of a PMSE cloud structure which varies both horizontally and in height, something which will influence the two radars differently due to their large difference in beam width. This shows up in Fig. 8 especially in the long relaxation phase (168 s) after the heater is switched off at $48 \mathrm{~s}$. Ideally the OCC should show a gradual relaxation back to the initial backscatter level. In our cases, the lowest layer shown in Fig. 7 indicates a relaxation-like variation for both radars, probably because this layer is relatively stable and extended (Fig. 2). For the two upper layers in Fig. 8 the situation is quite different. MORRO shows no relaxation except possibly in cycle 54 . VHF shows a relaxation in the upper layer but no relaxation in the layer at $85 \mathrm{~km}$. The relaxation time in these two layers in the upper height region of PMSEs appears to be close to $100 \mathrm{~s}$, which is considerably longer than what we found for the low layers shown in Fig. 7. The relaxation times is determined by the rate at which the dust particles lose their excess charge and the electron gradients return to their preheating value. This should have a connection to differences in the ion densities in the upper and lower PMSE region and to dust sizes since the ion-dust collision rate is proportional to ion density and to dust radius squared. If very small dust particles, e.g. meteoric smoke particles, are involved in the overshoot process, they may contribute to a rapid relaxation since they will quickly lose their negative charge by photodetachment (Havnes and Kassa, 2009; Rapp, 2009). Such particles may be more abundant in the lower parts of the PMSE region if they are released from NLC particles as they start to evaporate.

The profiles for MORRO and VHF for the upper two layers in Fig. 8 are well described by present model results for dust particles of sizes of $10 \mathrm{~nm}$ or lower (e.g. Biebricher and Havnes, 2012; Fig. 12). This agrees with the picture that dust particles are formed high up in the PMSE region and grow as they sink down into the lower layers. The upper layers are therefore expected to contain relatively small dust particles, while larger particles are found mainly in the low layers
(Nussbauer et al., 1996; von Zahn and Bremer, 1999; Kaifler et al., 2011), where they are expected to eventually evaporate. For the low layer in cycles 52 to 55 in Fig. 7, the observations resemble those of the low layer at cycles 42 to 45 except that we now generally see a more pronounced instantaneous decrease in the backscatter after the heater is switched on, and we see a slower recovery and a smaller total increase in backscatter during the heater-on period, followed by relatively strong overshoots, especially for VHF. Many of the differences in OCC between high and low PMSE layers can be ascribed to differences in electron heating and in neutral gas density. The heating effect in the PMSE region is primarily dependent on the total electron content below the region of interest, which leads to heater wave absorption, causing the lower parts of the PMSE region to be heated more than its upper parts (Belova et al., 1995; Kero et al., 2000; Kassa et al., 2005). With a lower neutral density in the upper PMSE region we will normally have the situation that the electron and ion ambipolar diffusion is more rapid there than in the lower layers. The higher electron temperature in the lower region when the heater is on will tend to cause a more rapid charge adjustment here than in the upper region. Both factors should favour situations where plasma adjustment dominates in the upper parts and charge adjustment in the lower parts of the PMSE region. In addition to this, there are more complicated combined dependencies on factors like electron and dust density, as well as dust sizes (Havnes, 2004; Scales, 2004; Biebricher et al., 2006; Scales and Chen, 2008; Mahmoudian et al., 2011; Biebricher and Havnes, 2012).

\section{Discussion and conclusions}

In agreement with previous studies (Bremer et al., 1996; Rapp et al., 2008), we find from the simultaneous MORRO and EISCAT VHF observations that MORRO shows more PMSE cloud cases than the VHF radar does. We often see that cloud structures generally appear in the MORRO observations before they appear in the VHF, and that they often persist for some time in MORRO after they disappear from the VHF. There is also a lack of direct correlation between the observed MORRO and VHF strengths. This is probably for a large part a consequence of the cross section of the MORRO radar beam being around 20 times larger than that of the VHF beam. We find that MORRO observes one to three layers for all the 64 heater cycles which were run, while VHF observes these layers for $69 \%$ of the cycles. MORRO and VHF observe two layers in 47 and $22 \%$ of the cycles, respectively. For three layers we find 13 and $6 \%$ respectively for MORRO and VHF. However, as shown in Fig. 3, right panel, we see the signs of an underlying correlation between the two radar backscatter strengths when we smooth the VHF data with a three-point running mean.

The statistics shown in Figs. 5 and 6 confirm the conclusions from model calculations (Scales, 2004; Mahmoudian et al., 2011; Biebricher et al., 2012) that there will normally 
be a considerable difference between the rate at which the plasma adjusts and dust is charged in structures scattering the MORRO radar beam and in the EISCAT VHF radar beam. On the other hand, it also appears from our statistics that the recovery of the VHF backscatter, during the time the heater is on, in a considerable number of cases is large enough to bring the backscatter up to a level well above that just before the heater was switched on. This can be problematic to reproduce simultaneously for both MORRO and VHF with the present models (Biebricher and Havnes, 2012).

If we compare the OCC profiles for MORRO and VHF for the two cloud layers at 85 and $86 \mathrm{~km}$ in Fig. 8, they appear to be of a type with a considerable and rapid decrease in backscatter signal as the heater is switched on, a modest recovery or decline during the heater-on period, followed by a rapid increase as the heater is switched off. These profiles can probably be well reproduced by present models. However, for the low single PMSE layer at 81.5 to $82 \mathrm{~km}$ shown in Fig. 7, we see a strong recovery during the heater-on period for both MORRO and VHF (see also Senior et al., 2014). The recovery can lead to levels of backscatter which are increased by a factor 2 to 3 above that just before the heater was switched on. The recovery profiles are similar for both radars. The VHF shows strong overshoots which can bring the backscatter level up to 3 to 5 times that before the heater was switched on. For MORRO we see modest to small overshoots except in cycle 53, where a large overshoot leads to a total increase up to $\sim 4$ times the undisturbed level. These profiles are not readily reproduced simultaneously for both radars by existing models (Biebricher and Havnes, 2012). The models predict that the recovery should be largest for the longer radar wavelength, while we observe that the initial recovery for the first 15-25 s after the heater is switched on most often is practically the same for both radars. This requires a substantial increase in dust charging, above that predicted in present models, and was also noted by Senior et al. (2014), who suggested that there is a need for a refinement of the dust charging models.

We note that the OCC in the upper PMSE layers, which are within the turbulent PMSE region, produce OCCs which are well described by present models. However, the low layers where this is not the case are situated in a region where little turbulence should be present (Rapp and Lübken, 2004). We suggest that this can lead to a situation where, in the high PMSE layers, turbulence keeps the dust structures freshly stirred up so that the dust sizes are well mixed and dust size distributions are the same at both MORRO and VHF scale lengths. For the low layer, the absence of turbulence should allow especially the smaller dust to diffuse out to form wider structures. The MORRO scattering in low layers may therefore be more influenced by smaller dust than what is the case for the VHF radar. We should also be aware that the overshoot models so far have been one-dimensional and that full three-dimensional models may modify some of the conclu- sions on plasma adjustment time as the heater is turned on and off.

The main conclusion of the present paper is that the list of effects included at present to model the reaction of the PMSEs to artificial electron heating is probably incomplete. This could possibly be coupled to incomplete charge modelling, where our results indicate that in many cases the modelled charging is too slow compared to the plasma diffusion time, at least down to structures scattering the EISCAT VHF radar beam.

Acknowledgements. This work was supported by grants from the Norwegian Science Council. We appreciate the helpful assistance by the EISCAT staff during the campaign. EISCAT is an international association supported by China, Finland, Japan, Norway, Sweden and the UK.

The topical editor A. J. Kavanagh thanks W. Scales and M. Rapp for help in evaluating this paper.

\section{References}

Belova, E. G., Pashin, A. B., and Lyatsky, W. B.: Passage of powerful HF radio wave through the ionosphere as a function of initial electron density profiles, J. Atmos. Terr. Phys., 57, 265-272, 1995.

Biebricher, A. and Havnes, O.: Non-equilibrium modeling of the PMSE Overshoot Effect revisited: A comprehensive study, J. Plasma. Phys, 78, 303-319. doi:10.1017/S0022377812000141, 2012.

Biebricher, A., Havnes, O., Hartquist, T. W., and La Hoz, C.: On the influence of plasma absorption by dust on the PMSE overshoot effect, Adv. Space Res., 38, 2541-2550, 2006.

Bremer, J., Hoffmann, P., Manson, A. H., Meek, C. E., Rüster, R., and Singer, W.: PMSE observations at three different frequencies in northern Europe during summer 1994, Ann. Geophys., 14, 1317-1327, doi:10.1007/s00585-996-1317-7, 1996.

Chen, C. and Scales, W. A.: Electron temperature enhancement effects on plasma irregularities associated with charged dust in the Earth's mesosphere, J. Geophys. Res., 110, A12313, doi:10.1029/2005JA011341, 2005.

Chen, C. and Scales, W. A.: Active perturbation of dust associated electron irregularities in the Earth's mesosphere: discrete charging effects, IEEE T. Plasma. Sci., 35, 731-735, 2007.

Chilson, P. B., Belova, E., Rietveld, M. T., Kirkwood, S., and Hoppe, U.-P.: First artificially induced modulation of PMSE using the EISCAT heating facility, Geophys. Res. Lett., 27, 38013804, 2000.

Cho, J. Y. N. and Röttger, J.: An updated review of polar mesosphere summer echoes: Observations, theory, and their relationship to noctilucent clouds and subvisible aerosols, J. Geophys. Res., 102, 2001-2020, doi:10.1029/96JD02030, 1997.

Friedrich, M. and Rapp, M.: News from the lower ionosphere: a review of recent developments, Surv. Geophys., 30, 525-559, doi:10.1007/s10712-009-9074-2, 2009.

Havnes, O.: Polar Mesospheric Summer Echoes (PMSE) overshoot effect due to cycling of artificial electron heating, J. Geophys. Res., 109, A02309, doi:10.1029/2003JA010159. 2004. 
Havnes, O. and Kassa, M.: On the sizes and observable effects of dust particles in polar mesospheric winter echoes, J. Geophys. Res, 114, D09209, doi:10.1029/2008JD011276, 2009.

Havnes, O. and Næsheim, L. I.: On the secondary charging effects and structure of mesospheric dust particles impacting on rocket probes, Ann. Geophys., 25, 623-637, doi:10.5194/angeo25-623-2007, 2007.

Havnes, O., Trøim, J., Blix, T., Mortensen, W., Næsheim, L. I., Thrane, E., and Tønnesen, T. : First detection of charged dust particles in the Earth's mesosphere, J. Geophys. Res., 101, 1083910847, 1996.

Havnes, O., La Hoz, C., Næsheim, L. I., and Rietveld, M. T.: First observations of the PMSE overshoot effect and its use for investigating the conditions in the summer mesosphere, Geophys. Res. Lett., 30, 2229, doi:10.1029/2003GL018429, 2003.

Havnes, O., La Hoz, C., Biebricher, A., Kassa,M., Meseret, T., Næsheim, L. I., and Zivkovic, T.: Investigation of the mesospheric PMSE conditions by use of the new overshoot effect, Phys. Scripta, 107, 70-78, 2004.

Havnes, O., Gumbel, J., Antonsen, T., Hedin, J., and La Hoz, C.: On the size distribution of collision fragments of NLC dust particles and their relevance to meteoric smoke particles, J. Atmos. Sol. Terr. Phys, 118, 190-198, 2014.

Hervig, M. E., Deaver, L. E., Bardeen , C. G., Russell III, J. M., Bailey, S. M., and Gordley, L. L.: The content and composition of meteoric smoke in mesospheric ice particles from SOFIE observations, J. Atmos. Sol.-Terr. Phy., 84-85, 1-6, 2012.

Hunten, D. M., Turco, R. P., and Toon, O. B.: Smoke and dust particles of meteoric origin in the mesosphere and stratosphere, J. Atmos. Sci., 37, 1342-1357, 1980.

Inhester, B., Klostermeyer, J., Lübken, F.-J., and von Zahn, U.: Evidence for ice clouds causing polar mesosphere summer echoes, J. Geophys. Res., 99, 20937-20954, 1994.

Kassa, M., Havnes, O., and Belova, E.: The effect of electron bite-outs on artificial electron heating and the PMSE overshoot, Ann. Geophys., 23, 3633-3643, doi:10.5194/angeo-233633-2005, 2005.

Kassa, M., Rapp, M., Hartquist, T. W., and Havnes, O.: Secondary charging effects due to icy dust particle impacts on rocket payloads, Ann. Geophys., 30, 433-439, doi:10.5194/angeo-30-4332012, 2012.

Kero, A., Bösinger, T., Pollari, P., Turunen, E., and Rietveld, M.: First EISCAT measurement of electron-gas temperature in the artificially heated D-region ionosphere, Ann. Geophys., 18, 12101215, doi:10.1007/s00585-000-1210-8, 2000.

Lie-Svendsen, O., Blix, T. A., Hoppe, U., and Thrane, E.: Modelling the plasma response to small-scale particle perturbations in the mesopause region, J. Geophys. Res., 108, 8442, doi:10.1029/2002JD002753, 2003.

Lübken, F.-J.: Thermal structure of the Arctic summer mesosphere, J. Geophys. Res., 104, 9135-9149, 1999.

Lübken, F.-J. and Höffner, J.: Experimental evidence for iceparticle interaction with metal atoms at the high latitude summer mesopause region, Geophys. Res. Lett., 31, L08104, doi:10.1029/2004GL019586, 2004.

Lübken, F., Hillert, W., Lehmacher, G., and von Zahn, U.: Experiments revealing small impact of turbulence on the energy budget of the mesosphere and lower thermosphere, J. Geophys. Res., 98, 20369-20384, 1993.
Lübken, F.-J., Rapp, M., Hoffmann, P.: Neutral air turbulence and temperatures in the vicinity of polar mesosphere summer echoes, J. Geophys. Res., 107, ACL 9-1-ACL 9-10, doi:10.1029/2001JD000915, 2002.

Kaifler, N., Baumgarten, G., Fiedler, J., Latteck, R., Lübken, F.J., and Rapp, M.: Coincident measurements of PMSE and NLC above ALOMAR $\left(69^{\circ} \mathrm{N}, 16^{\circ} \mathrm{E}\right)$ by radar and lidar from 19992008, Atmos. Chem. Phys., 11, 1355-1366, doi:10.5194/acp-111355-2011, 2011.

Kelley, M. C., Farley, D. T., and Röttger, J.: The effect of cluster ions on anomalous VHF backscatter from the summer polar mesosphere, Geophys. Res. Lett., 14, 1031-1034, 1987.

Mahmoudian, A. and Scales, W. A.: On the signature of positively charged dust particles on plasma irregularities in the mesosphere, J. Atmos. Sol.-Terr. Phy., 104, 260-269, doi:10.1016/j.jastp.2012.12.002, 2012.

Mahmoudian, A., Scales, W. A., Kosch, M. J., Senior, A., and Rietveld, M.: Dusty space plasma diagnosis using temporal behavior of polar mesospheric summer echoes during active modification, Ann. Geophys., 29, 2169-2179, doi:10.5194/angeo-292169-2011, 2011.

Megner, L.: Funneling of Meteoric Material into the Polar Winter Vortex, Proc. 17th Int. Conf. on Nucleation and Atmospheric Aerosols, Galway, Ireland, edited by: O'Dowd, G. D. and Wagner, P. E., 860-864, 2007.

Næsheim, L. I., Havnes, O., and La Hoz, C.: A comparison of polar mesosphere summer echo at VHF $(224 \mathrm{MHz})$ and UHF $(930 \mathrm{MHz})$ and the effects of artificial electron heating, J. Geophys. Res., 113, D08205, 2008.

Nussbaumer, V., Fricke, K.-H., Langer, M., Singer, W., and von Zahn, U.: First simultaneous and common-volume observations of NLC and PMSE by lidar and radar, J. Geophys. Res., 101, 19161-19167, 1996.

Ogurtsov, M. G. and Raspopov, O. M.: Possible impact of interplanetary and interstellar dust fluxes on the Earth's climate, Geomagn. Aeronomy, 51, 275-283, 2011.

Pedersen, A., Troim, J., and Kane, J.: Rocket measurement showing removal of electrons above the mesopause in summer at high latitudes, Planet. Space Sci., 18, 945-947, 1969.

Plane, J. M. C.: A time-resolved model of the mesospheric Na layer: constraints on the meteor input function, Atmos. Chem. Phys., 4, 627-638, doi:10.5194/acp-4-627-2004, 2004.

Raizada, S., Rapp, M., Lübken, F.-J., Höffner, J., Zecha, M., and Plane, J. M. C.: Effect of ice particles on the mesospheric potassium layer at spitsbergen (78 N), J. Geophys. Res. 112, D08307, doi:10.1029/2005JD006938, 2007.

Rapp, M.: Charging of mesospheric aerosol particles: the role of photodetachment and photoionization from meteoric smoke and ice particles, Ann. Geophys., 27, 2417-2422, doi:10.5194/angeo-27-2417-2009, 2009.

Rapp, M. and Lübken, F.-J.: Electron temperature control of PMSE, Geophys. Res. Lett., 27, 3285-3288, 2000.

Rapp, M. and Lübken, F.-J.: On the nature of PMSE: electron diffusion in the vicinity of charged particles revisited, J. Geophys. Res., 108, 8437, 2003.

Rapp, M. and Lübken, F.-J.: Polar mesosphere summer echoes (PMSE): Review of observations and current understanding, Atmos. Chem. Phys., 4, 2601-2633, doi:10.5194/acp-4-2601-2004, 2004. 
Rapp, M. and Thomas, G. E.: Modeling the microphysics of mesospheric ice particles: assessment of current capabilities and basic sensitivities, J. Atmos. Sol.-Terr. Phy., 68, 715-744, 2006.

Rapp, M., Strelnikova, I., Latteck, R., Hoffmann, P., Hoppe, U.-P., Häggström, I., and Rietveld, M. T.: Polar mesosphere summer echoes (PMSE) studied at Bragg wavelengths of $2.8 \mathrm{~m}, 67 \mathrm{~cm}$, and $16 \mathrm{~cm}$, J. Atmos. Sol.-Terr. Phy., 70, 947-961, 2008.

Rietveld, M. T., Kohl, H., and Kopka, H.: Introduction to ionospheric heating at Troms $\varnothing$ 1. Experimental overview, J. Atmos. Terr. Phys., 55, 577-599, 1993.

Robertson, S., Horányi, M., Knappmiller, S., Sternovsky, Z., Holzworth, R., Shimogawa, M., Friedrich, M., Torkar, K., Gumbel, J., Megner, L., Baumgarten, G., Latteck, R., Rapp, M., Hoppe, U.-P., and Hervig, M. E.: Mass analysis of charged aerosol particles in NLC and PMSE during the ECOMA/MASS campaign, Ann. Geophys., 27, 1213-1232, doi:10.5194/angeo-271213-2009, 2009.

Scales, W. A.: Electron temperature effects on small scale plasma irregularities associated with charged dust in the earths mesosphere, IEEE T. Plasma Sci., 32, 724-730, 2004.

Scales, W. A. and Chen, C.: On initial enhancement of mesospheric dust associated plasma irregularities subsequent to radiowave heating, Ann. Geophys., 26, 2265-2271, doi:10.5194/angeo-262265-2008, 2008.
Senior, A., Mahmoudian, A., Pinedo, H., La Hoz, C., Rietveld, M. T., Scales, W. A., and Kosch, M. J.: First modulation of high-frequency polar mesospheric summer echoes by radio heating of the ionosphere, Geophys. Res. Letters, 41, 5347-5353, doi:10.1002/2014GL060703, 2014.

She, C. Y., Williams, B. P., Hoffmann, P., Latteck, R., Baumgarten, G., Vance, J. D., Fiedler, J., Acott, P., Fritts, D. C., Lübken, F.-J.: Simultaneous observations of sodium atoms, MLC and PMSE in the summer mesopause region above ALOMAR, Norway (691N, 121E), J. Atmos. Sol.-Terr. Phy, 68, 93-101, doi:10.1016/j.jastp.2005.08.014, 2006.

Theon, J. S., Nordberg, W., Katchen, L. B., and Horvath, J. J.: Some Observations on the Thermal Behavior of the Mesosphere, J. Atmos. Sci., 24, 428-438. doi:10.1175/15200469(1967)024<0428:SOOTTB>2.0.CO;2, 1967.

von Zahn, U. and Bremer, J.: Simultaneous and common-volume observations of noctilucent clouds and polar mesosphere summer echoes, Geophys. Res. Lett., 26, 1521-1524, 1999.

von Zahn, U. and Meyer, W.: Mesopause temperatures in polar summer, J. Geophys. Res., 94, 14647-14650, doi:10.1029/JD094iD12p14647, 1989. 